Brit. F. vener. Dis. (1970), 46, 37

\title{
Demonstration of virus particles in human genital
} warts

\author{
J. D. OR I E L \\ Department of Venereal Diseases, St. Thomas' Hospital, London \\ JUNE D. ALMEIDA \\ Department of Virology, Royal Postgraduate Medical School, London
}

WHILE the pathology and virology of human skin warts have received considerable attention in the last few years, little work has been done to establish the relationship of genital warts to warts in general, or even to establish if these lesions are of viral origin.

The viral aetiology of the human skin wart (verruca vulgaris, plana, and plantaris) is now well established. By use of the electron microscope, particles having the morphology of viruses have been shown in thin sections and by the shadow cast and negativestaining techniques. The virus particles appear spherical and have a diameter of $550 \AA$ in shadow cast and negatively-stained preparations (Strauss, Shaw, Bunting and Melnick, 1949; Williams, Howatson and Almeida, 1961), but appear smaller in thin sections owing to dehydration and fixing processes (Bunting, 1953). Particles with similar morphology have been found in the skin and mucosal warts of rabbits, dogs, and cattle (Crawford and Crawford, 1963); these are, however, antigenically distinct from each other and from human skin wart virus (Le Bouvier, Sussman and Crawford, 1966). There is no evidence as yet of antigenic diversity between the viruses found in different clinical types of skin wart in man.

In skin warts, virus particles are found in the nuclei of the outer layers of the stratum spinosum, in the stratum granulosum, and in aggregates in the stratum corneum. As in the Shope papilloma (Stone, Shope, and Moore, 1959), the virus first appears in association with the nucleolus of the affected cell, and particles increase in number as the cell moves outward in the epidermis. Eventually virus particles can occupy the whole nucleus, often appearing in pseudocrystalline arrays in the keratin. Rupture of the nuclear membrane may occasionally release some particles, but otherwise virus does not appear in the cytoplasm (Charles, 1960; Almeida, Howatson and Williams, 1962).

Received December 10, 1968, but publication delayed at authors' request.
The nuclear basophilic inclusions seen by light microscopy in skin warts are shown by electron microscopy to be aggregates of virus particles (Almeida and others, 1962). The cytoplasmic eosinophilic inclusions, on the other hand, have been shown to be non-viral in nature and are thought to represent deranged keratohyalin development.

Few studies have been undertaken on genital warts. These lesions have cytological similarities to skin warts, and some basophilic inclusions were reported in one series (Blank, Buerk, and Weidman, 1951). It is frequently stated that they are caused by the same virus as is responsible for skin warts, the differences in appearance and behaviour of the lesions being accounted for by the variations in the fine structure of the epidermis in which the virus develops. The experimental evidence for this is indirect and rests on transfer experiments (Waelsch, 1917; Serra, 1924; Goldschmidt and Kligman, 1958) in which inoculations of unfiltered and filtered extracts of penile warts on to the skin in other parts of the body have, on occasion, been followed by the development of plane or common warts in these sites. These experiments have been few and the inoculum has in all cases been penile wart material, vulval and anal wart extracts not having been used; furthermore, skin wart extracts have never to our knowledge been successfully inoculated on to the genitals. The results of such transfer experiments are difficult to substantiate and interpret. Electron microscope observations on genital warts have been conflicting, so that the viral aetiology of genital warts is uncertain and the identity of any virus with that of skin warts is, in fact, unproved.

In an attempt to elucidate this problem, the virological techniques used for the study of skin warts were applied to genital warts to ascertain whether a consistent identification of virus particles can be made in these lesions and whether such particles bear any resemblance morphologically and in their distribution in the tissues to skin wart virus. 


\section{Material and methods}

A series of 26 white patients with genital warts (fifteen male and eleven female) attending the Department of Venereal Diseases at St. Thomas' Hospital were studied. Eleven male patients had penile warts and the other four, three of whom were admitted homosexuals, had anal warts. All eleven female patients had vulval warts. Two of the males and one female had gonorrhoea, three males non-gonococcal urethritis, and one female had candidiasis. The warts had been present for periods of from 2 weeks to 1 year (average $4 \frac{1}{2}$ months).

Warts were removed from 23 of these patients with a scalpel after first removing any excess of mucus by gently wiping with cotton wool.

One vulval wart was fixed in 4 per cent. methanol-free paraformaldehyde followed by Palade's sucrose-osmic acid fixative, dehydrated in ethanol, and embedded in Epon. Ore micron sections were examined by light microscopy to select a suitable area for electron microsscopy, and thin sections were then cut with a glass knife in an L.K.B. ultratome, mounted on suitable grids, stained with uranyl acetate and lead citrate, and then examined in a Philips 300 electron microscope. In addition, thick sections of this wart were stained with haematoxylin and eosin.

The 22 warts to be examined by negative staining were stored in dry sterile bottles at $-20^{\circ} \mathrm{C}$. until required. In the first few specimens examined, individual warts were thoroughly ground in a glass homogenizer with a little sand and a few drops of water, and the preparation was then clarified by low-speed centrifugation, the resultant supernatant being used for electron microscopy. In view of the small size of most of the lesions, differential centrifugation was not attempted. It was later realized not only that such thorough destruction of the wart was unnecessary, but that better electron microscope specimens were obtained by simple disruption of the outer layers. Therefore, in later specimens, the wart was very lightly ground with a few drops of water in a small pestle and mortar, the resulting fluid being aspirated but not centrifuged. It was also found that satisfactory demonstration of viral particles could be obtained without removing the wart, and in three cases, two vulval and one anal, the lesion was simply scraped in situ with a small wooden spatula, the resulting material being transferred to $0.5 \mathrm{ml}$. distilled water in a small screw-capped bottle and stored at $-20^{\circ} \mathrm{C}$. until required for use.

In all cases, a drop of the wart extract was mixed on a glass slide with a drop of 3 per cent. aqueous phosphotungstic acid that had been adjusted to $\mathrm{pH} 6.0$ with sodium hydroxide, and a small amount of this mixture was allowed to dry on a 400 mesh formvar-carbon coated grid before examination in a Philips 300 electron microscope.

\section{Results}

\section{(1) HISTOPATHOLOGY}

The vulval wart selected for histopathology showed papillomatosis, marked acanthosis, and areas in $\triangle$ which there were large vacuolated cells in the upper part of the stratum spinosum and in the stratum granulosum. The stratum corneum overlying these areas was thickened, with shredding of the keratin. These features are typical of genital warts.

\section{(2) ULTRATHIN SECTIONS}

Thin sections of this vulval wart were cut from a vacuolated-cell area. In these sections particles typical of virus were seen in some nuclei in the upper part of the stratum granulosum. They were spherical and of uniform size; in some cases they were scattered irregularly throughout the nucleus, sometimes (Fig. 1) with margination of the remaining nuclear material. In other nuclei (Fig. 2), definite aggregates were seen, amounting in a few cases (Fig. 3) to a crystalline array. The aggregates were small on the whole and in no case occupied the entire nucleus. Only a small proportion of the nuclei were thus affected and no areas of particle formation were seen in the cytoplasm. The particles themselves had a dense core with surrounding less dense material; morphologically and in their grouping they bore a close resemblance to other papilloma viruses such as human common wart and Shope papilloma.

Another type of inclusion was seen in these preparations; this (Fig. 4) consisted of large groups of ragged particles in the cytoplasm, adjacent to the nuclei. These have not been seen in skin warts and their nature is obscure; it is suggested that they may be glycogen granules. Dense spherical osmophilic bodies were also seen in the cytoplasm of occasional cells (Fig. 5); these resembled the osmophilic inclusions present in thin sections of ordinary skin warts, which have been identified with the eosinophilic inclusions seen in the light microscope (Almeida and others, 1962).

\section{(3) NEGATIVE STAINING}

In negatively-stained specimens from warts that had been completely homogenized, undoubted virus particles were found in small numbers in ten out of

Fig. 1 Part of a thin section of a nucleus from the stratum granulosum of a vulval wart. The chromatin shows marked margination, and the central part of the nucleus is occupied by scattered virus particles. $\times 41,000$.

Fig. 2 Portion of another nucleus from the stratum granulosum, showing a much higher concentration of virus particles than in Fig. 1. This type of virus distribution is frequently found in common skin warts. $\times 41,000$.

Fig. 3 One of the rare pseudocrystalline arrays of virus found in this study. $\times 64,000$. 


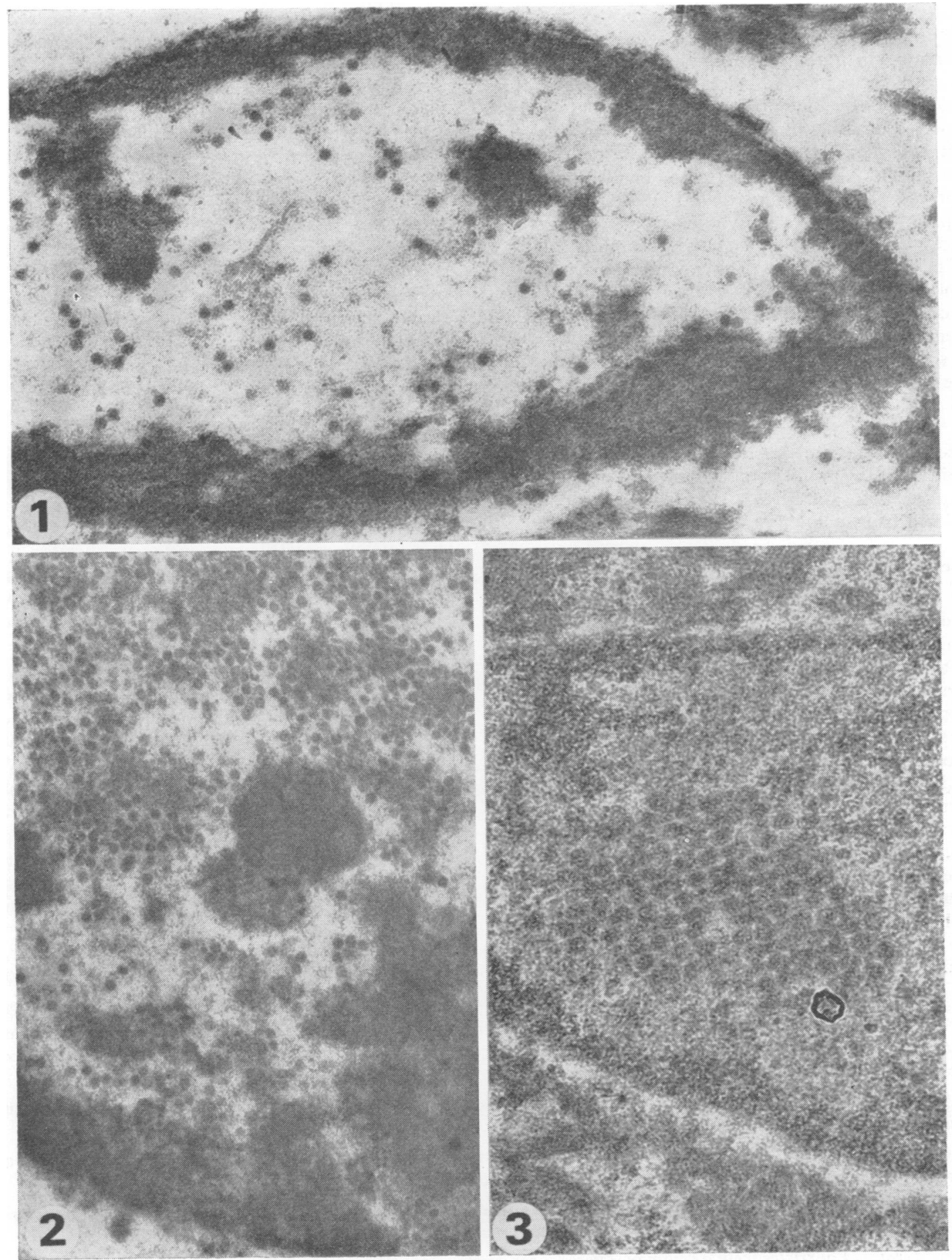


twenty cases (Fig. 6). This led us to speculate that the preparatory technique used, while suitable for ordinary skin warts, was not sufficiently sensitive for the frequently minute pieces of material available. Because of this, later specimens were only lightly disrupted, and it was immediately apparent that this approach yielded a much higher proportion of specimens in which virus particles could be identified. Fig. 7 shows a group of two particles found in one of these preparations. Altogether, virus particles were found in thirteen out of 25 wart extracts examined.

The particles themselves appear spherical, but display cubic symmetry in the arrangement of their subunits (Horne and Wildy, 1961). Diameter measurements were made on all the particles available, but the small numbers and frequently disrupted appearance of the virus make the figures obtained not too satisfactory. However, the range obtained, 480-580 $\AA$, did not seem to differ appreciably from measurements of control skin wart particles made under the same conditions (Fig. 8). There did not appear to be any morphological difference between virus particles obtained from penile, vulval, and anal sources.

\section{Discussion}

The results of electron microscopy of genital wart material so far reported have been conflicting. Zimmer (1964) had difficulty in finding any virus particles in the thin sections of one penile and five vulval warts he examined, but eventually found predominantly cytoplasmic particles of diameter from $200-800 \AA$. These particles bore no resemblance to the $550 \AA$ diameter particles found in skin warts. Melczer (1965) on the other hand, who examined thin sections of seven penile warts, found in five of these aggregates of nuclear virus of $400-500 \AA$ diameter, without crystalline arrangement; in the other two he found large amounts of this material in the cytoplasm. Detailed study of the morphology was not possible, but he was of the opinion that he had seen papillomatype virus in his preparations and that this corresponded in appearance and distribution to skin wart virus as described by other investigators. He concluded that the identity of the virus of genital warts and skin warts was highly probable. His identification of particles in the cytoplasm in great quantity is a significant difference from experience with skin warts, where the virus is exclusively nuclear.

Dunn and Ogilvie (1968) examined twelve specimens of genital wart material (the source of each was not specified) in thin sections, and found particles $360-470 \AA$ in diameter in the nuclei of cells in the stratum granulosum in one specimen. Negative staining of extracts of single warts revealed no virus particles, but on pooling and homogenizing the twelve specimens they were able to find a few undoubted virus particles of diameter $460 \AA$.

The question of size is of importance for virus particles having a morphology similar to that of the skin wart virus. There exists a group of predominantly oncogenic viruses that were previously described as papova viruses (Melnick, 1962). This term was used to describe viruses which have in common a DNA core, display a cubic capsid with a disputed either 42 or 72 subunit construction, thermal resistance, a slow growth cycle, and multiplication within the cell nucleus. The group contains two subgroups:

(i) The virus particles are found in the skin warts of man and in the skin and mucosal warts of other mammals and are of average diameter $550 \AA$;

(ii) The virus particles are smaller, average diameter $450 \AA$, contain less DNA, and comprise the viruses of polyoma, $\mathrm{SV} 40, \mathrm{~K}$ virus, and the polyomatype viruses found in certain cases of demyelinating brain disease (Howatson, Nagai, and Zurhein, 1965). The reality of these groupings has been questioned, but no satisfactory alternative has been suggested.

Since a certain amount of variation in size is found in any virus particle population, it is necessary to carry out a considerable number of measurements before a mean diameter can be estimated. The numbers of particles that we have obtained in this study were not sufficient to enable us to do this. However, the measurements that we did obtain showed no signi-

Fig. 4 One of the numerous granular inclusions present in several of the warts examined. While their exact nature is not known, it seems likely that they represent accumulations of glycogen. Care must be taken that such inclusions, which are present in the cytoplasm, are not confused with virus particles. $\times 40,000$.

Fig. 5 This paranuclear inclusion can be identified with the eosinophilic inclusions of light microscopy. They are indistinguishable from those found in common skin warts. $\times 41,000$.

Fig. 6 Over 50 per cent. of lesions examined by the negative-staining technique revealed small numbers of undoubted virus particles. One such particle, from a penile wart, is illustrated here. $\times 300,000$.

Fig. 7 Example of result obtained when genital warts were only very lightly disrupted. More numerous particles were present and could be easily identified against the rather greater amount of background material. $\times 300,000$.

Fig. 8 Group of particles from a common skin wart for comparison with Figs 6 and $7 . \times 300,000$. 

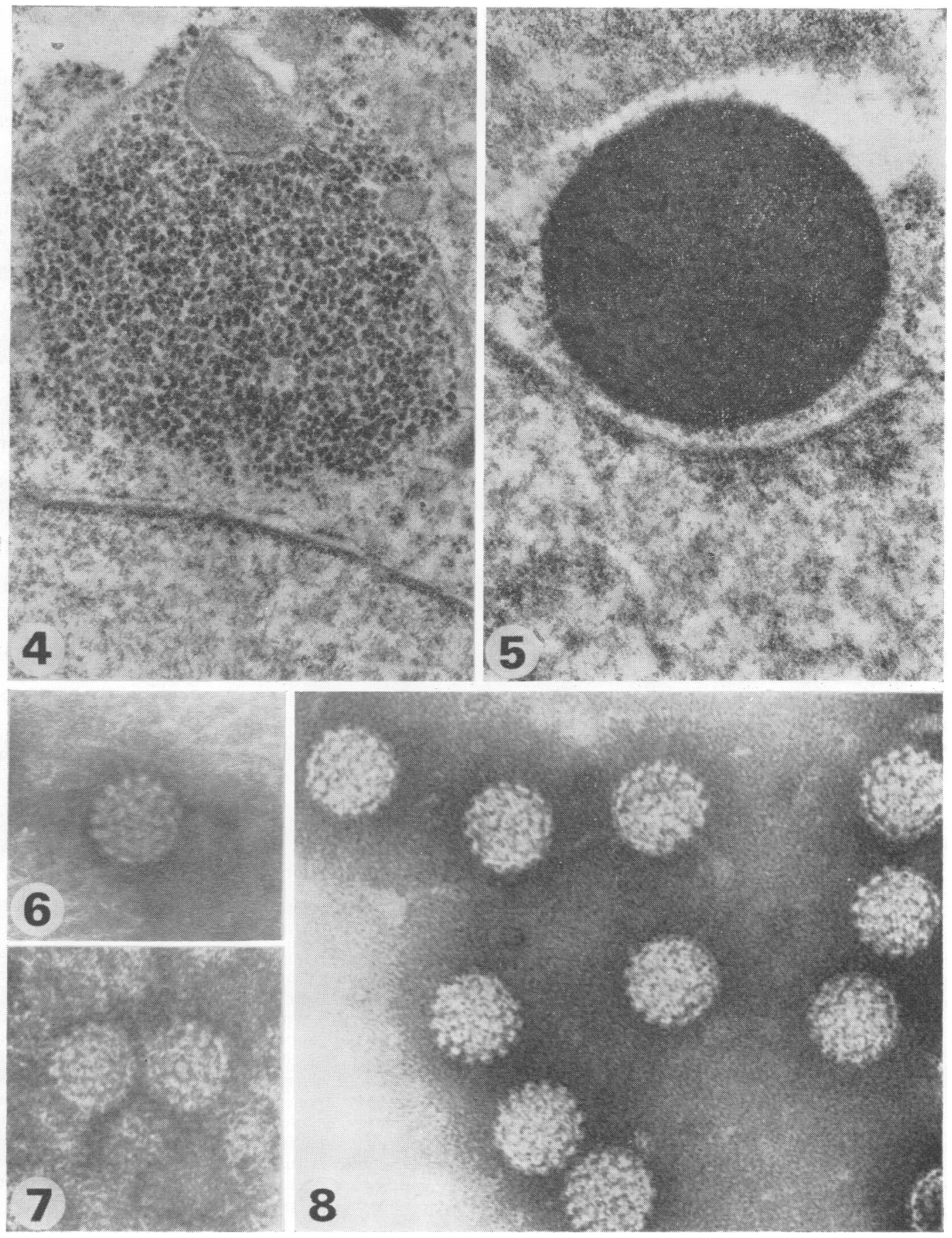
ficant variation from those taken on similarly prepared skin wart virus. In addition, the distribution of virus within nuclei in the thin section preparation had more in common with the papilloma viruses than with viruses such as polyoma.

However, because of the difficulty in obtaining sufficient quantities of virus, the question cannot at present be fully answered, and it is almost certain that the only satisfactory answer will come from immunological studies (Almeida and Goffe, 1965) which will reveal whether or not there is an antigenic relationship between the viruses of skin and genital warts. At present we are attempting to collect suffcient material in order to use this approach.

It is of interest that the concentration of particles is so low in the extracts we have examined; taking the threshold level of the microscope as being about $10^{6}$ particles $/ \mathrm{ml}$. for viruses of this type, the specimens were always near the limiting level. The experience of Zimmer (1964), who found no particles identifiable with wart virus in his preparations, and of Dunn and Ogilvie (1968), who found virus in only one of twelve sections examined, is consistent with this. In none of our specimens were there the dense crystalline arrays in thin sections and the high particle concentration in negatively-stained extracts which are frequently seen in skin wart preparations; it appears that genital warts, which are rapidly proliferative and highly contagious, have nevertheless a low concentration of mature virus. This may be due to rapid desquamation of the surface of the lesions in the moist environment of the genitals, together with poor keratinization, the virus being washed off the surface of the warts and not retained in the keratin.

\section{Summary}

Intranuclear virus particles have been demonstrated in thin sections of a vulval wart; in their morphology and distribution, they resemble similar particles previously found in thin sections of human skin warts.

Using the electron microscope technique of negative staining, it has been possible to identify virus particles in thirteen out of 25 genital warts examined. Insufficient numbers of particles were obtained to establish with certainty the mean diameter of the virus concerned, but the particles seemed to have more in common with the true papilloma viruses than with those of the polyoma group.

We are grateful to Dr. I. W. Whimster for preparing the sections used in this study for both light and electron microscopy. We also wish to thank Dr. C. S. Nicol and Prof. A. P. Waterson for help and encouragement in this undertaking.

J.D.O. is in receipt of a grant from the Endowments Committee, St. Thomas' Hospital, and J.D.A. is supported by a grant from the Medical Research Council.

\section{References}

ALmeIdA, J. D., and Goffe, A. P. (1965). Lancet, 2, 1205.

-, Howatson, A. F., and Williams, M. G. (1962). f. invest. Derm., 38, 337.

Blank, H., BuERK, M., and Weidman, F. (1951). Ibid., 16, 19.

Bunting, H. (1953). Proc. Soc. exp. Biol. (N.Y.), 84, 327.

Charles, A. (1960). Dermatologica (Basel), 121, 193.

CRAWFORD, L. V., and CRAWFORD, E. M. (1963). Virology, 21, 258.

DunN, A. E. G., and OGILvIE, M. M. (1968). F. Ultrastruct. Res., 22, 282.

GolDSCHMIDT, H., and KLIGMAN, A. M. (1958). f. invest. Derm., 31, 175.

HORNE, R. W., and WILDY, P. (1961). Virology, 15, 348.

Howatson, A. F., Nagai, M., and ZU Rhein, G. M. (1965). Canad. med. Ass. F., 93, 379.

Le Bouvier, G. L., Sussman, M., and Crawford, L. V. (1966). F. gen. Microbiol., 45, 497.

MELCZER, N. (1965). Hautarzt, 16, 150.

MelNiCK, J. L. (1962). Science, 135, 1128.

SERRA, A. (1924). G. ital. Mal. vener., 65, 1808.

StONE, R. S., SHOPE, R. E., and MOORE, D. H. (1959). F. exp. Med., 110, 543.

Strauss, M. J., Shaw, E. W., Bunting, H., and Melnick, J. L. (1949). Proc. Soc. exp. Biol. (N.Y.), 72, 46.

WaELSCH, L. (1917). Arch. Derm. Syph. (Wien), 124, 625.

Williams, M. G., Howatson, A. F., and Almeida, J. D. (1961). Nature (Lond.), 189, 895.

ZIMMER, S. (1964).Zbl. Gynäk., 86, 1116.

Mise en évidence de particules virales dans les végétations vénériennes humaines

SOMMAIRE

Des particules virales, intranucléaires, ont été mises en évidence dans des coupes de végétations vénériennes vulvaires; par leur morphologie et leur situation, elles ressemblent aux particules similaires trouvées antérieurement dans les coupes de verrues cutanées humaines.

Au microscope électronique, avec la technique de la coloration en négatif, on a pu identifier des particules virales chez treize des vingt-huit cas de végétations vénériennes génitales examinés. Le nombre des particules observé fut insuffisant pour établir avec certitude le diamètre moyen du virus, mais ces particules semblent se rapprocher plus du virus des vrais papillomes que de ceux du groupe polyoma. 